\title{
Evaluation of denaturing high performance liquid chromatography for the mutational analysis of the MEN1 gene
}

\author{
Michel Crépin ${ }^{1}$, Pascal Pigny1,2, Fabienne Escande ${ }^{1,2}$, Catherine Cardot Bauters ${ }^{4}$, \\ Alain Calender ${ }^{5,6}$, Sylvain Lefevre ${ }^{5}$, Marie-Pierre Buisine ${ }^{1,2}$, Nicole Porchet ${ }^{1,2}$ and \\ Marie-Françoise Odou ${ }^{1,3}$ \\ ${ }^{1}$ Unité Fonctionnelle d'Oncologie - Laboratoire de Biochimie, Hormonologie, Métabolisme-Nutrition, Oncologie - Eurasanté- CHRU Lille, Rue du Docteur Yersin, \\ 59037 Lille Cedex,France \\ ${ }^{2}$ Institut de Médecine Prédictive et de Recherche Thérapeutique, IFR 114, Faculté de Médecine H. Warembourg - Lille, 59037 France -Université de Lille 2 \\ ${ }^{3}$ Faculté des Sciences Pharmaceutiques et Biologiques - Lille, 59006 France-Université de Lille 2 \\ ${ }^{4}$ Clinique d'endocrinologie, de diabétologie et métabolisme Marc Linquette-CHRU Lille, 59037 France \\ ${ }^{5}$ Laboratoire de Génétique et Cancer- UMR CNRS - Lyon, 69437 France \\ ${ }^{6}$ Secrétaire Général du Groupe d’Etude des Tumeurs Endocrines (GTE)
}

(Requests for offprints should be addressed to M-F Odou at Laboratoire de Biochimie; Email: mf-odou@chru-lille.fr)

\begin{abstract}
The identification of mutations in the MEN1 gene causing MEN1 has represented a challenge since the cloning of the gene in 1997 because of the lack of mutation hot-spots in the gene and the lack of phenotype-genotype correlations. The use of denaturing high performance liquid chromatography (DHPLC), a high throughput, reliable and automated heteroduplex-based technique, is the ideal for mutation detection in MEN1. In this work, DHPLC was optimised for the screening of the nine coding exons and splice junctions of MEN1. Thanks to collaboration between two French laboratories recognised as reference centres for genotypic MEN1 diagnosis (Lyon and Lille), a blind retrospective study conducted in a cohort of 160 unrelated MEN1 probands with (or without) known germline mutations was undertaken to evaluate the sensitivity of DHPLC. We were able to detect 101 different sequence variations by DHPLC, distributed in the 10 analysed DNA fragments and corresponding to $100 \%$ of mutation detection compared with direct sequencing. $1 \cdot 2 \%$ of samples were considered as false positive, exhibiting a heterogenous profile. DHPLC did not detect five cases of deletion or duplication of complete exons, neither did direct sequencing, showing the limits of the technique. Nevertheless, the method appeared to allow automated, rapid and low-cost mutation detection with high accuracy. Direct sequencing can be then applied to identify the sequence variations on the targeted DNA fragments showing heterozygous profile by DHPLC. In conclusion, genotypic diagnosis of MEN1 can benefit from DHPLC in terms of efficacy, rapidity and cost.
\end{abstract}

Journal of Molecular Endocrinology (2006) 36, 369-376

\section{Introduction}

High sensitivity in detection of DNA sequence variations is fundamental for mutation analysis in disease associated genes. Well established techniques for mutation detection range from relatively simple methods called scanning methods, e.g. single strand conformation polymorphism (SSCP) and heteroduplex analysis (Crépin et al. 2003) to more complex procedures (also as scanning methods or as specific methods), e.g. direct sequencing, protein truncation test, denaturing gradient gel electrophoresis (DGGE) and enzymatic or chemical cleavage methods (Tchernitchko et al. 1999, Nedelcheva et al. 2001). However, the most sensitive methods are often very labour intensive and expensive. Ideally, the methods used for mutation analysis of a large number of DNA fragments should be sensitive, non hazardous, relatively inexpensive and fully or at least semiautomated to minimise time and later costs. Rapid turn over time is also of obvious importance for clinicians and their patients. These criteria appear to be met to a high degree for the method called denaturing high performance liquid chromatography (DHPLC; Xiao \& Oefner 2001). This technique is based on the detection of heteroduplexes in PCR products by ion-pair reverse phase high performance liquid chromatography (Oefner \& Underhill 1998). One of the advantages of this method is the use of automated instrumentation, leading to a high speed analysis. DHPLC has been successfully used for the detection of mutation of several genes 
associated with diseases such as $\mathcal{N F 1}$ (O'Donovan et al. 1998), BRCA1 and BRCA2 (Wagner et al. 1999); hMLH1 and hMSH2 (Holinski-Feder et al. 2003), VHL (Klein et al. 2001).

One of these genes for which mutations predispose to familial cancers is MEN1. The MEN1 gene is located on chromosome $11 \mathrm{q} 13$ and spans $9 \mathrm{~kb}$. It was cloned in 1997 by Chandrasekharappa et al., and the European Consortium on MEN1 (1997). Deleterious heterozygous mutations of this oncosuppressor gene predispose to Multiple Endocrine Neoplasia type 1 (MEN1), which is an autosomal dominant inherited tumour syndrome (OMIM 131100) characterized by tumours of parathyroid, entero-pancreatic neuroendocrine tissue and anterior pituitary (Pannett \& Thakker 1999, Schussheim et al. 2001). More than 300 deleterious germline mutations are scattered throughout the coding region of the gene and no obvious hot-spot has been identified (Giraud et al. 1998, Agarwal et al. 2004). There is currently no evidence of genotype/phenotype correlations (Marx et al. 1999, Wautot et al. 2002). As a consequence, all the expressed MEN1 exons, including exon/intron boundaries, need to be screened for mutation detection. For these reasons, a sensitive automated approach for mutation scanning was desirable. Owing to the above mentioned advantages of using DHPLC, we decided to evaluate the sensitivity and specificity of DHPLC as a first intention method for MEN1 mutation analysis in a population of patients.

\section{Materials and methods}

\section{Patients}

With the aim of evaluating DHPLC as a screening mutation technique, a blind retrospective study on 160 anonymised DNA samples was undertaken (in Lille). The samples were obtained from non-related French patients with MEN1 syndrome, previously screened for MEN1 mutations by direct sequencing (in Lyon). All patients gave their informed consent for the genetic analysis. Genomic DNA was extracted from whole venous blood with QIAAMP DNA blood Maxi kit (Qiagen, Courtabeuf, France) following the manufacturers' instructions. Additional DNA samples from affected and non affected patients were used as positive and negative controls, respectively. They were collected and prepared using the same conditions.

\section{PCR amplification}

The coding sequence of MEN1 (exons 2-10) was amplified from purified DNA using the primers previously described by Crépin et al. (2003) and selected from the sequence published in 1997 by Chandrasekharappa et al. (U93237·1). Exons 2 and 10 were amplified in two partially overlapping DNA fragments and exons 5 and 6 together. This was necessary to homogenise the size of the DNA fragments ranging from 192 to $369 \mathrm{bp}$.

Amplifications were carried out by PGR in a $50 \mu \mathrm{l}$ reaction volume containing $25 \mathrm{pM}$ of each primer, 0.5 $\mathrm{U}$ of Hot Star Taq polymerase (Qiagen) and $75 \mathrm{ng}$ of genomic DNA. Amplifications were performed with the following 'touchdown' PCR conditions : initial denaturation at $94{ }^{\circ} \mathrm{C}$ for $12 \mathrm{~min}$; 9 cycles of: denaturation at $95{ }^{\circ} \mathrm{C}$ for $30 \mathrm{~s}$, annealing with a decrease of $1{ }^{\circ} \mathrm{C} /$ cycle from 63 to $55^{\circ} \mathrm{C}$ for $90 \mathrm{~s}$, primer extension at $72^{\circ} \mathrm{C}$ for $90 \mathrm{~s} ; 26$ cycles of: $30 \mathrm{~s}$ at $95^{\circ} \mathrm{C}, 90 \mathrm{~s}$ at $55^{\circ} \mathrm{C}$, and $90 \mathrm{~s}$ at $72{ }^{\circ} \mathrm{C}$; then a final elongation step at $72{ }^{\circ} \mathrm{C}$ for 5 min.

\section{DHPLC analysis}

Blind DHPLC analysis was performed on a wave DNA fragment analysis system (Transgenomic, San Jose, CA, USA). Each PCR product was denaturated for $5 \mathrm{~min}$ at $95{ }^{\circ} \mathrm{C}$ and then gradually re-annealed by decreasing the sample temperature from 95 to $25^{\circ} \mathrm{C}$ (with a temperature ramp of $1.75^{\circ} \mathrm{C} / \mathrm{min}$ ) over a period of $40 \mathrm{~min}$. Two to five $\mu \mathrm{l}$ of PCR product was then applied to a pre-heated C18 reversed-phase column based on non porous poly(styrene-divinylbenzene) particles (DNASep, Transgenomic) and eluted with a mobile phase consisting of a mixture of $0 \cdot 1 \mathrm{M}$ triethylammonium acetate $\mathrm{pH} 7 \cdot 0$ (TEAA) (Transgenomic) and $0 \cdot 1 \mathrm{M}$ TEAA with $25 \%$ acetonitrile (Transgenomic) in a linear gradient, at a flow rate of $1.5 \mathrm{ml} / \mathrm{min}$. Gradient parameters were determined by size and GC content of the amplicons. Heteroduplexes and homoduplexes were detected by monitoring the absorbance at $260 \mathrm{~nm}$.

The condition for mutation analysis is based on the melting behaviour of the wild type sequence of the DNA fragment (Jones et al. 1999) rather than by its length. Temperature for successful resolution of heteroduplex molecules was determined by using the WaveMaker software (Transgenomic) and the Stanford DHPLC program (available at: www.insertion.stanford.edu/ melt.html). From the sequence of each fragment, the algorithm calculates the melting behaviour, the optimal analysis temperature for each domain corresponding to 80-90\% of $\alpha$-helical fraction. During the optimisation phase, a few mutated samples for each DNA fragment were additionally run up to $2{ }^{\circ} \mathrm{C}$ above and below of the predicted temperatures, with $0 \cdot 1{ }^{\circ} \mathrm{C}$ increments, to select the optimal temperatures for detection of sequence variations. Most of the exons required two to three temperatures for mutation analysis due to the different melting domains in the corresponding DNA fragment. Thus the softwares indicated a mean temperature for mutation detection but adjustment was necessary because some sequence variations were difficult to 
Table 1 Temperatures selected for DHPLC analysis for each DNA fragment
Fragment size

(bp)

\section{Exon/ \\ (DNA fragment)}

$2 /(2 A B)$

$2 /(2 C D)$

3

4

$5+6$

8

$10 /(10 \mathrm{AB})$

$10 /(10 C)$

\section{3}

263

305

192

297

250

217

245

369

253
Analysis temperatures

$65.1^{\circ} \mathrm{C} / 67.6^{\circ} \mathrm{C}$ $60.4{ }^{\circ} \mathrm{C} / 61.9^{\circ} \mathrm{C} / 63.4{ }^{\circ} \mathrm{C}$ $62.3^{\circ} \mathrm{C} / 64.5{ }^{\circ} \mathrm{C}$ $60.9^{\circ} \mathrm{C} / 62.5^{\circ} \mathrm{C}$ $60.2^{\circ} \mathrm{C}$

$61.5^{\circ} \mathrm{C} / 64{ }^{\circ} \mathrm{C}$

$62.1^{\circ} \mathrm{C}$

$61.6{ }^{\circ} \mathrm{C} / 64.1{ }^{\circ} \mathrm{C}$

$67.2^{\circ} \mathrm{C}$

$62.8{ }^{\circ} \mathrm{C}$ visualise. The selected analysis temperatures are summarised in table 1 .

\section{DNA sequencing}

As the study was retrospective, all of the 160 DNA samples had already been analysed by direct sequencing of the whole coding region of $M E N ~ 1$, using $100 \mathrm{ng}$ of purified DNA product and an ABI PRISM Big Dye terminator cycle sequencing ready reaction kit (Applied Biosystems, Courtaboeuf, France). Sequencing was performed on the ABI PRISM 377 DNA sequencer (Applied Biosystems). Each DNA fragment harbouring a modified DHPLC pattern compared with the negative control was further analysed by sequencing.

\section{Results}

The conditions for mutation analysis of the various DNA fragments were determined on the basis of the data obtained with a few mutated samples with previously known sequence variations. For the study, 160 DNA samples were analysed for the 10 DNA fragments covering the coding exons of MEN1 (so representing 1600 DNA fragments). Due to the insufficient amount of DNA for some samples, only 1473/1600 DNA fragments could be amplified (92\%).

The analysis of one DNA sample was completed in a few hours which include PCR, generation of heteroduplexes, and elution of each of the 10 DNA fragments at one to three different temperatures.

DHPLG analysis enabled us to detect 213 DNA fragments with sequence variation, corresponding to 101 different sequence variations covering all the tested DNA fragments. These are listed in table 2. For most cases, detection of abnormal elution profiles was performed at the two or three selected temperatures, comparing to a negative control profile. Nevertheless, for some of them located on specific melting temperature domains, only one tested temperature revealed a heterogenous profile, justifying to select multiple temperatures for analysis. (e.g: c88-16C $>\mathrm{G}$; c1364C $>$ T).

As it was a retrospective blind analysis, all these sequence variations had already been identified by sequencing. These have been recorded in the French GTE database (Groupe d'étude des Tumeurs Endocrines; http://www.fichiergte.com) and also most of them are in international databases such as HGMD (Human Gene Mutation Database) (http://uwcmmlls. uwcm.ac.uk.html).

Among these sequence variations, some corresponded to known polymorphisms. We found them with a frequency close to the data published, i.e.: c88-16C $>$ G: 16/120 (13.33\%); c545C > T (pS145S): 11/149 (7.38\%); c622 G>A (pR171Q): 4/151 (2.65\%); c1364C>T (pD418D): 65 /141(46.1\%); c1731 G>A (pA541T): 6/ $151(3.97 \%)$. Few other sequence variations, not recorded as polymorphisms, were detected in more than one sample. It is noticeable that virtually each sequence variation leads to a specific elution profile and that the same sequence variation in different samples leads to the same profile, displaying a good reproducibility. Figures 1 and 2 show few examples of mutation profiles in different DNA fragments (compared with negative controls).

No sequence variation was missed by DHPLC analysis, except the five samples with deletions or duplications of complete exons, which do not lead to the promotion of heteroduplexes and which are also missed by sequencing. Only semi-quantitative methods, such as quantitative multiplex PCR of short fluorescent DNA fragments (QMPSF; Casilli et al. 2002) are able to assess exon copy number and detect this type of mutation. Such methods are performed when MEN1 syndrome is clinically evident and no MEN1 mutation is found by conventional methods. Thus, the sensitivity of the method can be considered to be $100 \%$ compared with sequence analysis (213/213 'positive' DNA fragments).

Some DNA fragments (18) exhibited heterogenous profiles (compared with the negative controls) without corresponding to any sequence variation, especially in the DNA fragments corresponding to exon 8. This could be due to the DNA quality or to the complexity or the heterogeneity of these DNA fragments. Out of 1260 negative DNA fragments by sequencing, 1242 showed a 'negative' DHPLC profile and 18 could be considered as false positive (if sequencing is the reference method). As a consequence, the specificity of the method can be considered to be $98.6 \%(1242 / 1260)$ due to these 18 doubtful DNA fragments which can be considered as 'false positive'. 
Table 2 Tabulation of 101 sequence variations detected by DHPLC

\begin{tabular}{|c|c|c|}
\hline & Sequence variation & Number of samples \\
\hline $\begin{array}{l}\text { Location } \\
\text { int1 }\end{array}$ & $c 88-16 C>G$ & (P) 16 \\
\hline ex2 & c117del & 1 \\
\hline ex2 & c177del & 1 \\
\hline ex2 & $\mathrm{c} 195 \mathrm{C}>\mathrm{T}$ & 1 \\
\hline ex2 & $c 223 C>G$ & 1 \\
\hline ex2 & $\mathrm{c} 255 \mathrm{G}>\mathrm{C}$ & 1 \\
\hline ex2 & c285del & 1 \\
\hline ex2 & c306_310dup & 4 \\
\hline ex2 & c318_319insGGTG & 1 \\
\hline ex2 & c337del & 1 \\
\hline ex2 & c357_360del & 1 \\
\hline ex2 & c359_363del & 1 \\
\hline ex2 & c382del & 2 \\
\hline ex2 & $\mathrm{c} 396 \mathrm{C}>\mathrm{T}$ & 1 \\
\hline ex2 & $c 402 C>T$ & 1 \\
\hline ex2 & $c 432 C>T$ & 1 \\
\hline ex2 & c437_438insGG & 1 \\
\hline ex2 & c464_466del & 1 \\
\hline ex2 & c485_486del & 1 \\
\hline ex2 & $\operatorname{c509\overline {C}}>A$ & 1 \\
\hline ex2 & c523del & 1 \\
\hline ex2 & $\mathrm{c} 541 \mathrm{~T}>\mathrm{G}$ & 1 \\
\hline ex2 & $c 545 \mathrm{C}>\mathrm{T}$ & (P) 11 \\
\hline int2 & $c 556-3 C>G$ & 1 \\
\hline ex3 & c562_563del & 2 \\
\hline ex3 & $c 576 \bar{G}>T$ & 1 \\
\hline ex3 & $c 577 G>A$ & 1 \\
\hline ex3 & $\mathrm{c} 581 \mathrm{G}>\mathrm{A}$ & (P) 1 \\
\hline ex3 & $\mathrm{c} 603 \mathrm{~T}>\mathrm{C}$ & 1 \\
\hline ex3 & $\mathrm{c} 622 \mathrm{G}>\mathrm{A}$ & (P) 4 \\
\hline ex3 & c644insT & 1 \\
\hline ex3 & $\mathrm{c} 645 \mathrm{G}>\mathrm{C}$ & 1 \\
\hline ex3 & c699_701del & 1 \\
\hline ex3 & c710_711insCA & 1 \\
\hline ex3 & c711_712dup & 1 \\
\hline ex3 & c738_741del & 1 \\
\hline ex3 & c747del & 1 \\
\hline ex3 & $\mathrm{c} 764 \mathrm{G}>\mathrm{T}$ & 1 \\
\hline int3 & $c 765-6 C>A$ & 1 \\
\hline int3 & {$[\mathrm{c} 765-6 \mathrm{C}>\mathrm{G} ; \mathrm{c} 765-3 \mathrm{~A}>\mathrm{G}]$} & 1 \\
\hline int3 & $\mathrm{c} 765-6 \mathrm{C}>\mathrm{T}$ & 1 \\
\hline ex4 & c776del & 1 \\
\hline ex4 & $\mathrm{c} 778 \mathrm{~T}>\mathrm{C}$ & 2 \\
\hline ex4 & $\mathrm{c} 804 \mathrm{C}>\mathrm{T}$ & 1 \\
\hline ex4 & c883insA & 1 \\
\hline ex5 & $c 905 G>A$ & 1 \\
\hline ex5 & c924insC & 1 \\
\hline ex5 & $c 934 G>A$ & 2 \\
\hline int5 & $c 934+5 G>A$ & 1 \\
\hline int5 & $c 934+35 G>A$ & 1 \\
\hline ex6 & $\mathrm{c} 951 \mathrm{G}>\mathrm{A}$ & 2 \\
\hline ex6 & c1016_1017del & 1 \\
\hline ex7 & $c 1041 \bar{A}>C$ & 1 \\
\hline ex7 & c1049T>G & 1 \\
\hline ex7 & $c 1051 G>C$ & 1 \\
\hline ex7 & c1077T >C & 1 \\
\hline ex7 & $c 1079 C>G$ & 1 \\
\hline ex7 & $c 1120 C>A$ & 2 \\
\hline ex7 & $\mathrm{c} 1131 \mathrm{~T}>\mathrm{C}$ & 1 \\
\hline ex7 & $c 1155 C>T$ & 1 \\
\hline
\end{tabular}

Table 2 Continued

\begin{tabular}{|c|c|c|}
\hline \multirow[b]{2}{*}{ Location } & Sequence variation & Number of samples \\
\hline & & \\
\hline int7 & $c 1159+1 G>A$ & 1 \\
\hline int7 & $c 1159+2 T>C$ & 1 \\
\hline ex8 & c1170del & 1 \\
\hline ex8 & $\mathrm{c} 1179 \mathrm{G}>\mathrm{C}$ & 1 \\
\hline ex8 & $c 1213 C>A$ & 1 \\
\hline ex8 & $c 1228 C>G$ & 1 \\
\hline ex9 & c1298_1301del & 1 \\
\hline ex9 & c1325del & 1 \\
\hline ex9 & $c 1353 C>T$ & 1 \\
\hline ex9 & $c 1362 G>A$ & 1 \\
\hline ex9 & $\mathrm{c} 1364 \mathrm{C}>\mathrm{T}$ & (P) 65 \\
\hline ex9 & c1374del & 1 \\
\hline ex9 & c1381insG & 1 \\
\hline ex9 & c1384_1386del & 1 \\
\hline ex9 & $c 1409 \bar{C}>T$ & $(P) 2$ \\
\hline ex9 & $c 1418 G>A$ & 1 \\
\hline ex9 & $c 1424 C>G$ & 1 \\
\hline int9 & c1460+1_1460+11del & 2 \\
\hline int9 & c1460+4del8insGTCTGT & 1 \\
\hline int9 & $\mathrm{c} 1461-1 \mathrm{G}>\mathrm{T}$ & 1 \\
\hline ex10 & c1486_1493dup & 1 \\
\hline ex10 & c1486_1508del & 2 \\
\hline ex10 & c1487delCinsACATAGT & 1 \\
\hline ex10 & $\mathrm{c} 1488 \mathrm{C}>\mathrm{T}$ & 3 \\
\hline ex10 & c1489ins17 & 1 \\
\hline ex10 & c1490_1501del12ins5 & 1 \\
\hline ex10 & c1583insC & 1 \\
\hline ex10 & c1593insC & 1 \\
\hline ex10 & c1634del & 1 \\
\hline ex10 & c1650del & 1 \\
\hline ex10 & c1650insC & 2 \\
\hline ex10 & c1656insG & 1 \\
\hline ex10 & $c 1689 C>T$ & 1 \\
\hline ex10 & c1699del & 1 \\
\hline ex10 & $\mathrm{c} 1716 \mathrm{C}>\mathrm{T}$ & 1 \\
\hline ex10 & $c 1728 \mathrm{C}>\mathrm{T}$ & 1 \\
\hline ex10 & $c 1731 G>A$ & $(P) 6$ \\
\hline ex10 & $\mathrm{c} 1774 \mathrm{G}>\mathrm{C}$ & 1 \\
\hline ex10 & $c 1774 G>A$ & 1 \\
\hline ex10 & c1780_1782del & 1 \\
\hline ex10 & c1782del & 1 \\
\hline & & 213 \\
\hline
\end{tabular}

Nomenclature according to HGVS recommendations; numbering based on MEN1 cDNA sequence (accession number U93236) (P), polymorphism

In case of any 'positive' DHPLG result (detection of abnormal profile in comparison to negative control), the sequence analysis remains essential for confirming and identifying the sequence variation.

\section{Discussion}

DHPLC mutation analysis for the MEN1 gene carried out in 160 French patients was rapid and sensitive. Standardisation of PCR conditions and semi-automation 

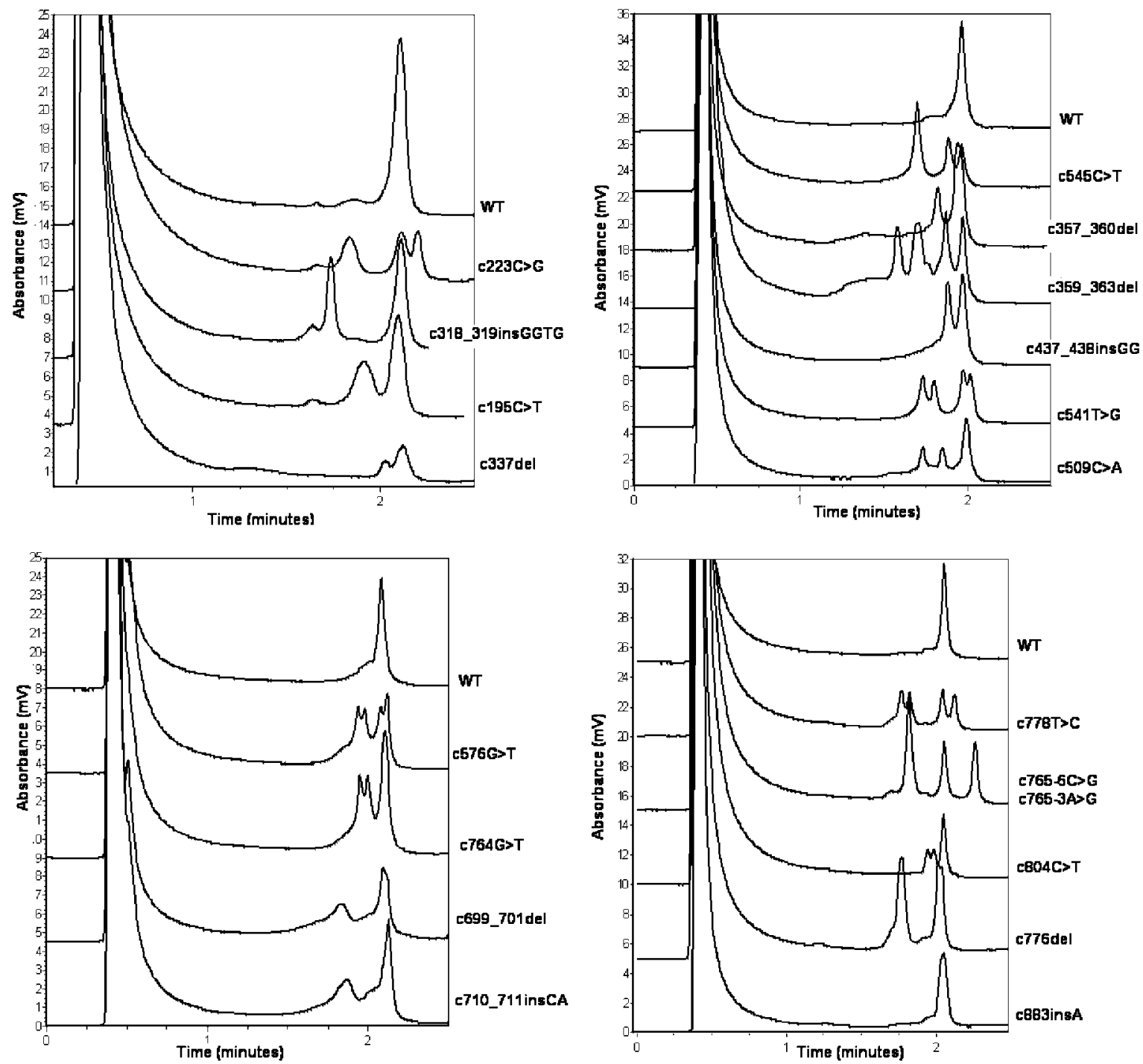

Figure 1 Representative DHPLC patterns in MEN1 DNA fragments (exon 2 to exon 4). From top to bottom and left to right, respectively, ex $2 \mathrm{AB}\left(67.6^{\circ} \mathrm{C}\right)$; ex $2 \mathrm{CD}\left(61.9^{\circ} \mathrm{C}\right)$; ex $3\left(64.5^{\circ} \mathrm{C}\right)$; ex $4\left(62.5^{\circ} \mathrm{C}\right)$.

of methodology allowed high throughput of analysis. We were able to detect 101 different sequence variations in MEN1, yielding a sensitivity of $100 \%$ compared with sequence analysis. Whatever the great heterogeneity of mutations responsible for MEN1 was, this blind analysis allowed us to conclude that the running conditions previously defined for each DNA fragment were optimised.

Specificity greatly depends on the purity of the PCR products. If the DHPLC instrument is used in carefully monitored conditions, according to robust standard operating procedures, this technique offers a high reproducibility. The previously used mutation screening strategy in our laboratory for MEN1 (Crépin et al. 2003) required the combination of the two techniques (MDGA and HMA) to yield $100 \%$ sensitivity and was therefore much more time consuming and expensive. Marsh et al. (2001) and Roberts et al. (2001) showed that DHPLG is well adapted to rapid mutation scanning. Due to frequent polymorphisms, especially in exon 9, DHPLC patterns could hide another mutation in the polymorphic DNA fragments. In these cases, DNA sequencing remained essential. Nevertheless, the mean rate of sequencing for MEN1 remained much lower than without use of DHPLC as a screening method. Consequently, the cost of MEN1 genotypic diagnosis was estimated as being five times cheaper with this strategy, compared with complete sequencing of the gene. This is in accordance with Sevilla et al. (2002) who made an economic analysis of BRCA1 testing by different 

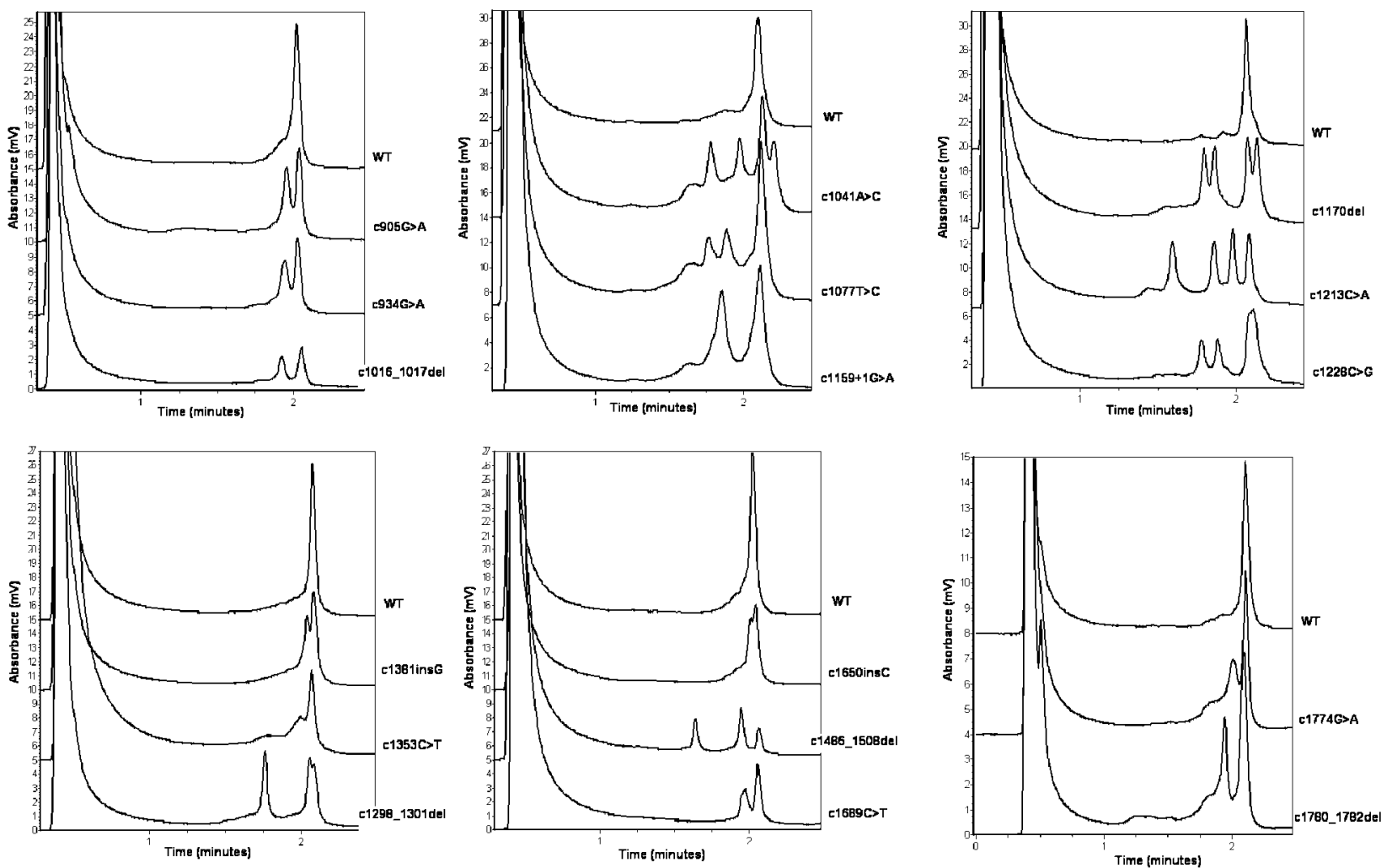

Figure 2 Representative DHPLC patterns in MEN1 DNA fragments (exon 5 to exon 10). From top to bottom and left to right, respectively, ex $5+6\left(60 \cdot 2^{\circ} \mathrm{C}\right)$; ex $7\left(64 \cdot 0^{\circ} \mathrm{C}\right)$; ex $8\left(62 \cdot 1^{\circ} \mathrm{C}\right)$; ex $9\left(64 \cdot 1^{\circ} \mathrm{C}\right)$; ex $10 \mathrm{AB}\left(67 \cdot 2^{\circ} \mathrm{C}\right)$; ex $10 \mathrm{C}\left(62 \cdot 8^{\circ} \mathrm{C}\right)$.

techniques and showed that DHPLG was by far cheaper than direct sequencing or other screening methods such as SSCP or DGGE.

Virtually each sequence variation led to a specific elution profile. Of course, the optimal resolution should show all four hetero- and homoduplexes fully resolved. In practice some mutations exhibited a better resolution than others because the stability of the heteroduplexes varied and the flanking base pairs created different surroundings (Van den Bosch et al. 2000). Therefore, our study allowed us to constitute a pattern database of more than 100 sequence variations for MEN1. Nevertheless, patterns need to be interpreted with great caution because in some cases, patterns corresponding to different sequence variation looked very similar to each other (e.g. figure 1, exon 5+6: c905 G>A and c934 G>A). The identification of mutations by sequencing remains essential, especially with MEN1, for which new mutations are found regularly.

Some authors showed that DHPLG was also able to detect a low-level of mosaicism (Emmerson et al. 2003, Hendy et al. 2003). It can thus be hypothesized that mosaicism could be underestimated for most genotypic analysis, because of the difficulty of detection by conventional methods. Takashima et al. (2001) estimated that DHPLC may perform better than conventional automated DNA sequence analysis for patient mutation detection. They described a number of sequence variations, not detected by direct DNA sequencing, that were detected by DHPLC. The collection of DHPLC heteroduplex fractions enabled us to subsequently identify the corresponding sequence variations.

DHPLC could also be applied to detection of somatic mutations in tumours, as shown by Liu et al. (1998), Lu et al. (2003) with p53 and ST7 genes in gastric carcinomas, or Gross et al. (1998) with p53 in ovarian tumours. In addition, the authors also used frequent polymorphisms to rapidly identify loss of heterozygosity $(\mathrm{LOH})$ in tumours, which is usually part of the mechanism encountered for tumour suppressor genes such as p53 but also MEN1 (Pannett \& Thakker 2001).

Whatever the performances of DHPLC, the characteristics of the method make the detection of complete deletion or duplication of exons impossible. However, SSCP, DGGE or sequence analysis exhibit the same limitations. These methods are therefore unsuitable for comprehensive mutation detection in diseases known to be associated with exon deletions or duplications as main mutational mechanism. Semi-quantitative methods are then needed to detect these large rearrangements. An 
elegant multiplex ligation-dependent probe assay has been recently described, related to the previously described multiplex amplifiable probe hybridization (Armour et al. 2000, Schouten et al. 2002). Lastly, various semi-quantitative multiplex fluorescent PCR protocols have been used to detect large rearrangements culminating in the so-called QMPSF (Casilli et al. 2002). Also more recently, some authors described a new, versatile and robust method to assess exon copy number, called multiplex PCR/liquid chromatography assay (Dehainault et al. 2004). Large deletions or duplications can also be assessed by high resolution comparative genome hybridization microarrays methodology (Porchet et al. 2004).

Mutational analysis of MEN1 achieved by complete sequence analysis of the nine coding exons and corresponding exon/intron boundaries is expensive and time consuming. It is clear that DHPLC is a reliable and economic way to screen out the DNA fragments of wild-type sequence and select only those showing evidence of sequence variations for nucleotide sequencing. This facilitates a broad genotypic screening in routine analysis of MEN1 in patients for whom the diagnosis of MEN1 is evoked on few clinical or biological arguments (for example hyperparathyroidism alone occurring at a young age), for early detection and treatment. It can also be useful for differential diagnosis because the clinical features of this disease are diverse. Park et al. (2003) screened for MEN1 mutations, by DHPLC, five MEN1 typical families but also one family with familial isolated hyperparathyroidism and one family with familial pituitary adenoma. Recent studies show that mutation testing for MEN1 remains justified for all patients with clinical typical criteria of MEN1 and also for isolated hyperparathyroidism cases (familial cases or sporadic cases in young people) (Cardinal et al. 2005). DHPLG takes up the challenge of extending the screening for other genes involved in neighboured syndromes, as done by Biasiotto et al. (2003) for hereditary hemochromatosis. Therefore, the phenotypic heterogeneity of the disorder could be grasped and genotype-phenotype correlations could be defined.

In conclusion, we propose a DHPLC protocol which was found to be reliable, cost effective, rapid, sensitive and specific for MEN1 mutation screening. Large genetic testing studies on MEN1 have recently been published (Cardinal et al. 2005, Ellard et al. 2005, Klein et al. 2005) but all were based on PCR sequencing of all the coding regions of MEN1. To our knowledge, it is the first time that the MEN1 gene has been evaluated on such a large number of samples by a screening method with $100 \%$ sensitivity, therefore allowing its use in routine analysis and avoiding systematic complete sequencing of the gene. DHPLC has become a standard pre-screening tool for mutation detection and Schollen et al. (2005) recently described a collaborative work from diagnostic laboratories with DHPLC expertise to develop standard operating procedures for quality assurance of molecular diagnostic tests performed with this system. In the same way, our study allows other laboratories to directly perform DHPLG mutation screening of the MEN1 gene with a robust validated method.

\section{Acknowledgements}

We are grateful to Prof. P Oeffner for discussion and expert advices about all aspects of DHPLC and to E Destailleur for her excellent technical assistance. This study was performed within the framework of GTE (Groupe d'Etude des Tumeurs Endocrines) and in the frame of a national network supported by GNRS (GDR no 2906). The authors declare that there is no conflict of interest that would prejudice the impartiality of this scientific work.

\section{References}

Agarwal SK, Lee Burns A, Sukhodolets KE, Kennedy PA, Obungu VH, Hickman AB, Mullendore ME, Whitten I, Skarulis MC, Simonds WF et al. 2004 Molecular pathology of the MEN1 gene. Annals of the New York Academy of Sciences 101 189-198.

Armour JA, Sismani C, Patsalis PC \& Cross G 2000 Measurement of locus copy number by hybridisation with amplifiable probes. Nucleic Acids Research 28 605-609.

Biasiotto G, Belloli S, Ruggeri G, Zanella I, Gerardi G, Corrado M, Gobbi E, Albertini A \& Arosio P 2003 Identification of new mutations of the HFE, Hepcidin, and Transferrin Receptor 2 genes by denaturing HPLC analysis of individuals with biochemical indications of iron overload. Clinical Chemistry 49 1981-1988.

Cardinal JW, Bergman L, Hayward N, Sweet A, Warner J, Marks L, Learoyd D, Dwight T, Robinson B, Epstein M et al. 2005 A report of a national mutation testing service for the MEN1 gene: clinical presentations and implications for mutation testing. Fournal of Medical Genetics 42 69-74.

Casilli F, Di Rocco ZC, Gad S, Tournier I, Stoppa-Lyonnet D, Frebourg T \& Tosi M 2002 Rapid detection of novel BRCA1 rearrangements in high-risk breast-ovarian cancer families using multiplex PCR of short fluorescent fragments. Human Mutation 20 218-226.

Chandrasekharappa S, Guru S, Manickam P, Olufemi S, Collins F, Emmert-Buck M, Debelenko L, Zhuang Z, Lubensky I, Liotta L et al. 1997 Positional cloning of the gene for multiple endocrine neoplasia-type 1. Science $\mathbf{2 7 6} 404-407$.

Crépin M, Escande F, Pigny P, Buisine MP, Calender A, GENEM, Porchet N \& Odou MF 2003 Efficient mutation detection in MEN1 gene using a combination of single-strand conformational polymorphism (MDGA(IM) and heteroduplex analysis. Electrophoresis 24 26-33.

Dehainault C, Laugé A, Caux-Moncoutier V, Pagès-Berhouet S, Doz F, Desjardins L, Couturier J, Gauthier-Villars M, Stoppa-Lyonnet D \& Houdoyer C 2004 Multiplex PCR/liquid chromatography assay for detection of gene rearrangements: application to RB1 gene. Nucleic Acids Research 32 e139.

Ellard S, Hattersley AT, Brewer CM \& Vaidya B 2005 Detection of a MEN1 gene mutation depends on clinical features and supports 
current referral criteria for diagnostic molecular genetic testing. Clinical Endocrinology 62 169-175.

Emmerson P, Maynard J, Jones S, Butler R, Sampson JR \& Cheadle JP 2003 Characterizing mutations in samples with low-level mosaicism by collection and analysis of DHPLC fractionated heteroduplexes. Human Mutation 21 112-115.

Giraud S, Zhang CX, Serova-Sinilnikova O, Wautot V, Salandre J, Buisson N, Waterlot C, Bauters C, Porchet N, Aubert JP et al. 1998 Germ-line mutation analysis in patients with MEN1 and related disorders. American Fournal of Human Genetics 63 455-467

Gross E, Kiechle M \& Arnold N 1998 Mutation analysis of $p 53$ in ovarian tumors by DHPLC. Fournal of Biochemical and Biophysical Methods 47 73-81.

Hendy GN, Minutti C, Canaff L, Pidasheva S, Yang B, Nouhi Z, Zimmerman D, Wei C \& Cole DE 2003 Recurrent familial hypocalcemia due to germline mosaicism for an activating mutation of the calcium sensing receptor gene. Fournal of Clinical Endocrinology and Metabolism 88 3674-3681.

Holinski-Feder E, Muller-Koch Y, Friedl W, Moeslein G, Keller G, Plaschke J, Ballhausen W, Gross M, Baldwin-Jedele K, Jungck M et al. 2003 DHPLC mutation analysis of the hereditary nonpolyposis colon cancer (HNPCC) gene hMLH1 and hMSH2. Fournal of Biochemical and Biophysical Methods 47 21-32.

Jones AC, Austin J, Hansen N, Hoogendoorn B, Oefner PJ, Cheadle JP \& O'Donovan MC 1999 Optimal temperature selection for mutation detection by denaturing HPLC and comparison to single-stranded conformation polymorphism and heteroduplex analysis. Clinical Chemistry 45 1133-1140.

Klein B, Weirich G \& Brauch H 2001 DHPLC-based germline mutation screening in the analysis of the VHL tumor suppressor gene: usefulness and limitations. Human Genetics 108 376-384.

Klein RD, Salih S, Bessoni J \& Bale AE 2005 Clinical testing for Multiple Endocrine Neoplasia type 1 in a DNA diagnostic laboratory. Genetics in Medicine 7 131-138.

Liu W, Smith DI, Rechtzigel KJ, Thibodeau SN \& James CD 1998 Denaturing high performance liquid chromatography (DHPLC) used in the detection of germline and somatic mutations. Nucleic Acids Research 26 1396-1400.

Lu C, Xu HM, Ren Q Ao Y, Wang ZN, Ao X, Jiang L \& Zhang X 2003 Somatic mutation analysis of $p 53$ and ST7 tumor suppressor genes in gastric carcinoma by DHPLC. World Fournal of Gastroenterology 9 2662-2665.

Marsh DJ, Theodosopoulos G, Howell V, Richardson AL, Benn DE, Proos AL, Eng C \& Robinson BG 2001 Rapid mutation scanning of genes associated with familial cancer syndromes using denaturing high performance liquid chromatography. Neoplasia 3 236-244.

Marx SJ, Agarwal SK, Kester MB, Heppner C, Kim YS, Skarulis MC, James LA, Goldsmith PK, Saggar SK, Park SY et al. 1999 Multiple endocrine neoplasia type 1: clinical and genetic features of the hereditary endocrine neoplasias. Recent Progress in Hormone Research 54 397-439.

Nedelcheva KV, Kelefiotis D, Kristensen T \& Borresen-Dale AL 2001 High- throughput methods for detection of genetic variation. Biotechniques 30 318-330.

O'Donovan MC, Oefner PJ, Roberts SC, Austin J, Hoogendoorn B, Guy C, Speight G, Upadhuyaya M, Sommer SS \& McGuffin P 1998 Blind analysis of denaturing high performance liquid chromatography as a tool for mutation detection. Genomics $5244-49$

Oefner PJ \& Underhill PA 1998 DNA mutation detection using denaturing high performance liquid chromatography. In: Current protocols in human genetics pp $7 \cdot 10: 1-7 \cdot 10 \cdot 12$. New York, Wiley.

Pannett AAJ \& Thakker RV 1999 Multiple endocrine neoplasia type 1. Endocrine Related Cancer 6 449-473.

Pannett AAJ \& Thakker RV 2001 Somatic mutations in MEN type 1 tumors consistent with the Knudson 'two-hit' hypothesis. Fournal of Clinical Endocrinology and Metabolism 86 4371-4374.
Park JH, Kim IJ, Kang HC, Lee SH, Shin Y, Kim KH, Lim SB, Kang SB, Lee K, Kim SY et al. 2003 Germline mutations of the MEN1 gene in Korean families with multiple endocrine neoplasia type 1 (MEN1) or MEN1- related disorders. Clinical Genetics 64 48-53.

Porchet N, Odou MF, Cardot-Bauters C, Quief S, Lignon S, Villenet C, Calender A, Pigny P \& Kerkaert JP 2004 Characterization of MEN1 gene deletion by high resolution CGH microarray in a large MEN1 family. Fournal of Internal Medicine 255720.

Roberts PS, Jozwiak S, Kwiatkowski DJ \& Dabora SL 2001 Denaturing high performance liquid chromatography (DHPLC) is a highly sensitive, semi-automated method for identifying mutations in the TSC1 gene. Fournal of Biochemical and Biophysical Methods 47 33-37.

Schollen E, Dequeker E, McQuaid S, Vankeirsbilck B, Michils G, Harvey J, Van den Akker E, Van Schooten R, Clark Z, Schrooten S et al. 2005 Diagnostic DHPLC Quality Assurance (DDQA): a collaborative approach to the generation of validated and standardized methods for DHPLC-based mutation screening in clinical genetics laboratories. Human Mutation 25 583-592.

Schouten JP, McElgunn CJ, Waaijer R, Zwijnenburg D, Diepvens F \& Pals G 2002 Relative quantification of 40 nucleic acids sequences by multiplex ligation-dependent probe amplification. Nucleic Acids Research 30 e 57.

Schussheim D, Skarulis M, Agarval S, Simonds W, Leeburns A, Spiegel A \& Marx S 2001 Multiple endocrine neoplasia type 1: new clinical and basic findings. Trends in Endocrinology and Metabolism $12173-178$.

Sevilla C, Moatti JP, Julian-Reynier C, Eisinger F, Stoppa-Lyonnet D, Bressac-de Paillerets B \& Sobol H 2002 Testing for BRCA1 mutations : a cost-effectiveness analysis European Fournal of Human Genetics 10 599-606.

Takashima H, Boerkoel CF \& Lupski JR 2001 Screening for mutations in a genetically heterogenous disorder: DHPLC versus DNA sequence for mutation detection in multiple genes causing Charcot-Marie-Tooth neuropathy. Genetics in Medicine 3 335-342.

Tchernitchko D, Lamoril J, Puy H, Robreau AM, Bogard C, Rosipal R, Gouya L, Deybach JC \& Nordmann Y 1999 Evaluation of mutation screening by heteroduplex analysis in acute intermittent porphyria: comparison with denaturing gradient gel electrophoresis. Clinical Chimica Acta 279 133-143.

The European Consortium On MEN 1. 1997 Identification of the multiple endocrine neoplasia type 1 (MEN1) gene. Human Molecular Genetic 6 1177-1183.

Van den Bosch B, De Coo RFM, Scholte HR, Nijland JG, Van den Bogaard R, De Visser M, De Die-Smulders CEM \& Smeets HJM 2000 Mutation analysis of the entire mitochondrial genome using denaturing high performance liquid chromatography. Nucleic Acids Research 28 e89.

Wagner T, Stoppa-Lyonnet D, Fleischmann E, Muhr D, Pages S, Sandberg T, Caux V, Moeslinger R, Langbauer G, Borg A et al. 1999 Denaturing high performance liquid chromatography detects reliably BRCA1 and BRCA2 mutations. Genomics 15 369-376.

Wautot V, Vercherat C, Lespinasse J, Chambe B, Lenoir GM, Zhang CX, Porchet N, Cordier M, Beroud C \& Calender A 2002 Germline mutation of MEN1 in multiple endocrine neoplasia type 1: search for correlation between phenotype and the functional domains of the MEN1 protein. Human Mutation 20 35-47.

Xiao W \& Oefner PJ 2001 Denaturing High performance Liquid Chromatography: a review. Human Mutation 17 439-474.

Received in final form 19 January 2006

Accepted 27 January 2006

Made available online as an Accepted Preprint 3 February 2006 